Document downloaded from:

http://hdl.handle.net/10251/77697

This paper must be cited as:

Ferrer López, S.; Ruiz Sánchez, T. (2013). Assessment of the degree of willingness to change from motorized travel modes to walking or cycling. Transportation Research Record. 2328(1):112-120. doi:10.3141/2382-13.

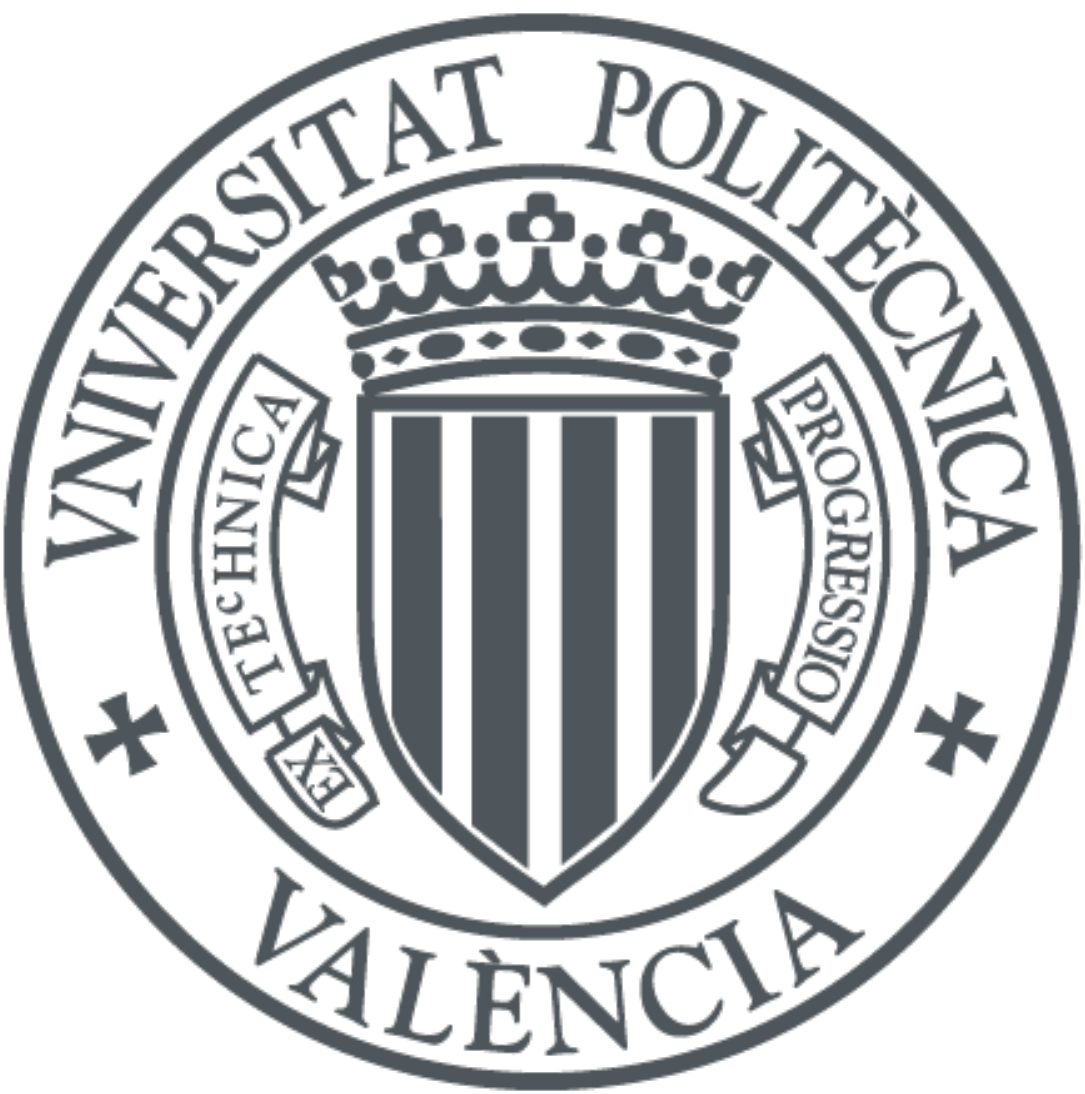

The final publication is available at

http://dx.doi.org/10.3141/2382-13

Copyright National Academy of Sciences

Additional Information 


\title{
Assessment of the Degree of Willingness to Change from Motorized Travel Modes to Walking or Cycling
}

\author{
Sheila Ferrer (*) \\ Ph.D. Candidate \\ Transport Department \\ School of Civil Engineering \\ Universidad Politécnica de Valencia \\ Camino de Vera s/n, 46022 Valencia, Spain \\ Tel: $(+34) 963877365$ \\ E-Mail: $\underline{\text { shferlo@upv.es }}$ \\ Tomás Ruiz \\ Assistant Professor \\ Transport Department \\ School of Civil Engineering \\ Universidad Politécnica de Valencia \\ Camino de Vera s/n, 46022 Valencia, Spain \\ Tel: (+34) 963877370, Fax: (+34) 963877370 \\ E-Mail: truizsa@tra.upv.es
}




\begin{abstract}
This paper presents an analysis of the degree of willingness to change from motorized travel modes to walking or cycling, with the aim is to reduce uncertainty between stated willingness to change and real shifts from car or transit to non-motorized transportation modes. Data was collected in the city of Valencia (Spain) using a novel data collection effort based on multiple survey methods. Respondents traveling by car or transit were asked about their willing to change to walking or cycling under the implementation of improvement measures to be selected. Then, a hypothetical scenario was presented to those respondents in which previously selected measures were implemented and they were supposed to be cycling or walking. In this scenario, the costs of their usual travel mode were gradually reduced until they gave up cycling or walking. Those decided to keep on walking or cycling are assumed to have a strong willingness to change.

A statistical analysis carried out using Heckman's sample selection model allow us to identify demographic, socioeconomic and travel-related factors influencing the degree of willingness to change. Results reveal that car users present a stronger willingness to switch to walking or cycling compared to transit users. In addition, older respondents show a stronger willingness to change to both walking and cycling. Work/school related journeys are less associated to walking than non-commuting journeys, but they are more related to cycling. Policy implications of the analysis results are highlighted.
\end{abstract}

\title{
KEYWORDS
}

Willingness to Change, Non-motorized Transport, Multiple Travel Data Collection Method 


\section{INTRODUCTION}

Car use is causing a number of harmful externalities including air pollution, congestion, traffic accidents or health quality reduction. Many government agencies and public health organizations have explicitly advocated more non-motorized travel mode use as a way of improving health (1). There is a growing interest in the literature in understanding people choice of sustainable travel modes, since many surveys and experience indicate that many people would prefer to drive less and rely more on alternative modes (2). They point out that there is a group of people who would like to cycle and walk, and could be persuaded to do it if they had better quality service (3).

\section{Willingness to change from car to more sustainable modes of transportation}

In 1997, Curtis and Headicar (4) tried to identify which car drivers were most likely to be the best targets for marketing non-car modes. Based on a survey of travel behavior among a sample of households, they found that most car commuters are highly car oriented and are not susceptible to mode change. Most susceptible to change were males, respondents in their 30s and those who undertake short distance work journeys of 5 miles or less. Part-time workers, younger (aged 20-24 years), older groups (older than 50 years) and those in the highest income group are least likely to be susceptible to change.

To examine whether people can be moved out of their cars to other more sustainable forms of transportation for the journey to work, Kingham et al. (5) surveyed a sample of employees in Hertfordshire, England. Surveys were a combination of revealed preference and stated preference questions. The results suggest that improved cycle paths and less traffic on roads would encourage respondents to cycle to work, but substantial changes in commuter mode away from the car will also require people to live closer to the workplace.

Wardman et al. (6) developed a mode choice model for the journey to work to predict the impact of different measures to encourage cycling. Most effective policy would combine improvements in en-route facilities, a daily payment to cycle to work and comprehensive tripend facilities. Males were found to be more likely to cycle than females, as well as being more likely to walk.

The potential for modal change of students and staff at the University of Western Australia was examined by Shannon et al. (7). An on-line questionnaire was completed by respondents with information about current travel behavior, barriers to using active modes of transportation and motivators. They measured the potential for change from drivers to active commuters and the results suggested that between 20 and 30 per cent of staff and students could be encouraged to change their travel behavior in the short term. For those living under 1 kilometer of University, 30 per cent stated that they could change to walking and about 25 per cent of those living under 8 kilometers could be encouraged to take up cycling.

Recently, the UK Department for Transport published the British Social Attitudes Survey (8) about public attitudes towards transportation for 2011. Among other questions, respondents were asked about their willingness to switch from car to more sustainable modes of travel. A proportion of 42 per cent of respondents agreed that they could easily walk many of the journeys of less than two miles they now travel by car, and 38 per cent could just easily cycle if they had a bike. Females were less likely to cycle than males in the same circumstances. 
The present research takes a step forward to better understand the stated willingness to change to walking or cycling for certain trips currently undertaken by car by assessing the degree of willingness to change, reducing the unpredictability between the stated behavior and real behavior. This novel approach is based on testing how strongly are respondents willing to change, once they have stated to be willing to. Respondents willing to change are presented with a hypothetical scenario where they have already changed to the non-motorized mode previously selected and where new policies permit reductions in travel costs that can persuade participants to come back to their cars; the willingness to change of those giving up walking/cycling is assessed as weak compared to those strongly willing to change that keep walking/cycling even when their costs are reduced by 90 per cent.

Thus, the overall objective of this paper is to identify demographic, socioeconomic and travel-related factors that lead to weaker or stronger willingness to change and to explore the main differences between the results observed for walking and cycling. The characteristics of the data used are described in the following section. This is followed by a description of the models used and a discussion of the factors influencing both the degree of willingness to switch to walking and cycling. The paper ends with some conclusions and policy implications.

\section{DATA CHARACTERISTICS}

\section{Survey methodology}

Surveys were carried out face-to-face on street with the help of handheld computers and paper/showcard material in spring of 2009. A total of 2.536 car and transit users were surveyed at parking spaces and bus/tram stops located throughout the city of Valencia when they were going to start their journey back home in the evening. First, they were asked about the type of activity undertaken before starting the current journey back home and about their usual travel mode for journeys with the same purpose. If respondents usual travel mode for that journey was neither car nor transit, then the survey was finished. Second, their travel time was collected and only those whose door-to-door travel time was less than 30 minutes and with destination in Valencia were accepted to be interviewed. This value was identified to be suitable for cycling and walking in prior focus groups and to cover the average distance traveled by motorized transportation modes in Valencia of 4.0 kilometers (9). This is also in line with the main findings of WALCYNG (10), which found that car trips shorter than $3-5 \mathrm{~km}$ could be replaced by walking or cycling.

In the first part of the survey, respondents who fulfilled all the requirements were asked if they would switch from car or transit to walking for journeys like the current one under the implementation of walking improvement measures. If respondents answered negatively to this question, they were prompted to explain the reasons for their response, and then they were asked the same question related to the willingness to cycle if cycling improvement measures were implemented. Similarly, if respondents answered negatively to this last question, they were prompted again to explain the reasons for their response and the survey was finished. For those willing to change to walking or cycling, the survey continued asking respondents several questions to estimate their monthly travel costs using the usual travel mode for the current journey. Only if respondents were willing to cycle, they were asked about bicycle availability, bicycle use frequency and knowledge of bike rental systems. 
In the second part, those respondents willing to change to walking or cycling participated in a stated tolerance experiment. Participants were suggested to select the minimum number of improvement measures required to change (Table 1).

TABLE 1 Walking and cycling improvement measures

\begin{tabular}{|c|c|}
\hline Walking measures & Cycling measures \\
\hline $\begin{array}{l}\text { 1. Sidewalks clear of obstacles and cleaner } \\
\text { (walkable) }\end{array}$ & $\begin{array}{l}\text { 1. Cycle lanes connected throughout the city and fully } \\
\text { segregated }\end{array}$ \\
\hline $\begin{array}{l}\text { 2. Maintenance improvements in the existing } \\
\text { sidewalks }\end{array}$ & $\begin{array}{l}\text { 2. Cycle lanes clear of obstacles, motorized vehicles } \\
\text { and pedestrians }\end{array}$ \\
\hline $\begin{array}{l}\text { 3. Sidewalk widening and development of new } \\
\text { walking paths }\end{array}$ & 3. Priority measures for cyclists \\
\hline 4. Priority measures for pedestrians & 4. Bike rental system in operation \\
\hline $\begin{array}{l}\text { 5. Control and reduction of noise pollution and } \\
\text { air pollution }\end{array}$ & $\begin{array}{l}\text { 5. Maintenance improvements in the existing cycle } \\
\text { lanes }\end{array}$ \\
\hline \multirow[t]{2}{*}{$\begin{array}{l}\text { 6. More pedestrian security: police presence or } \\
\text { other security surveillance }\end{array}$} & $\begin{array}{l}\text { 6. New cycle lanes in lower traffic streets (lower } \\
\text { pollution) }\end{array}$ \\
\hline & 7. Shower/changing facilities at destination \\
\hline
\end{tabular}

A photo showcard describing several walking/cycling improvement measures identified in previous focus groups was presented to respondents and they were asked: "Under what of the following improvement measures could you imagine yourself walking/cycling for your current journey?. Respondents were asked about walking or cycling depending on their willingness to change evaluated previously.

Finally, a hypothetical scenario was presented to respondents willing to switch to assess their degree of willingness to change. The following scenario was presented to participants: "Imagine that the measure(s) you have selected is/are implemented, and you are cycling/walking for your current journey. A new policy allows car/transit costs to be reduced. Would you keep cycling/walking if your car/transit costs were reduced by 10 percent and your current monthly costs were _ $\mathrm{x}$ _ euros?. Costs' reductions were gradually increased by $10 \%$ until the answer was "Yes" or costs were reduced more than 90 per cent. The question was customized to each respondent considering the usual travel mode for the current journey, the non-motorized travel mode respondent was willing to change to, and the estimated monthly usual travel costs. The question was framed as a "Yes/No" choice rather than the frequently used open-ended form "What is the minimum amount you would accept ..." because making a series of dichotomous choices simplifies the task and may be less likely to stimulate "strategic bias" (11). 


\section{Descriptive analysis}

A total of 1433 individuals who fulfilled conditions were surveyed about their willingness to cycle for their current journey. The number of respondents who declared not to be willing to switch to cycling was 782, which represent 54.6 per cent. One third of these respondents argued that travel distance was too long or journey duration was too high. Those who think cycling is uncomfortable or do not like it represent 26 per cent.

The number of respondents who answered positively was 651 , which represent 45.4 per cent. Males and females stated to be willing to cycle to the same extent (Table 2). The younger the respondent, the more willing was to cycle. Car users were slightly less willing to cycle than transit users.

TABLE 2 Stated Willingness to Cycle

\begin{tabular}{|c|c|c|c|c|c|}
\hline \multirow[b]{2}{*}{ Gender } & \multirow[b]{2}{*}{ Age } & \multicolumn{2}{|c|}{ Total respondents* } & \multicolumn{2}{|c|}{ Willing to cycle $(\%)$} \\
\hline & & Car users & Transit users & Car users & Transit users \\
\hline \multirow[t]{5}{*}{ Female } & $18-30$ & 151 & 80 & $49.0 \%$ & $70.0 \%$ \\
\hline & $31-50$ & 228 & 87 & $44.3 \%$ & $58.6 \%$ \\
\hline & $51-65$ & 57 & 41 & $21.1 \%$ & $36.6 \%$ \\
\hline & $>65$ & 11 & 17 & $18.2 \%$ & $11.8 \%$ \\
\hline & No data & 16 & 8 & $0.0 \%$ & $0.0 \%$ \\
\hline Total female & & 461 & 235 & $40.9 \%$ & $54.0 \%$ \\
\hline \multirow[t]{5}{*}{ Male } & $18-30$ & 115 & 146 & $53.9 \%$ & $65.8 \%$ \\
\hline & $31-50$ & 185 & 161 & $38.4 \%$ & $49.1 \%$ \\
\hline & $51-65$ & 19 & 50 & $26.3 \%$ & $20.0 \%$ \\
\hline & $>65$ & 4 & 32 & $25 \%$ & $12.5 \%$ \\
\hline & No data & 5 & 11 & $0.0 \%$ & $0.0 \%$ \\
\hline Total male & & 328 & 409 & $42.4 \%$ & $48.0 \%$ \\
\hline
\end{tabular}

*Total number of car/transit users surveyed to the corresponding gender and age.

To study the willingness to walk, 1412 car or transit users fulfilling conditions were surveyed. About one fifth of participants stated to be willing to change, a lower result compared to respondents' stated willingness to cycle. Both male and female transit users seem to be more willing to switch to walking than car users (Table 3). 
TABLE 3 Stated Willingness to Walk

\begin{tabular}{|c|c|c|c|c|c|}
\hline \multirow[b]{2}{*}{ Gender } & \multirow[b]{2}{*}{ Age } & \multicolumn{2}{|c|}{ Total respondents* } & \multicolumn{2}{|c|}{ Willing to walk (\%) } \\
\hline & & Car users & Transit users & Car users & Transit users \\
\hline \multirow[t]{5}{*}{ Female } & $18-30$ & 164 & 60 & $14.63 \%$ & $25.0 \%$ \\
\hline & $31-50$ & 223 & 79 & $8.9 \%$ & $19.0 \%$ \\
\hline & $51-65$ & 60 & 44 & $11.7 \%$ & $34.1 \%$ \\
\hline & $>65$ & 11 & 22 & $18.2 \%$ & $50 \%$ \\
\hline & No data & 16 & 11 & $0.0 \%$ & $0.0 \%$ \\
\hline \multicolumn{2}{|c|}{ Total female } & 474 & 216 & $11.2 \%$ & $25.9 \%$ \\
\hline \multirow[t]{5}{*}{ Male } & $18-30$ & 111 & 129 & $14.4 \%$ & $31.0 \%$ \\
\hline & $31-50$ & 195 & 150 & $19.0 \%$ & $32.0 \%$ \\
\hline & $51-65$ & 26 & 52 & $30.8 \%$ & $28.8 \%$ \\
\hline & $>65$ & 4 & 33 & $0.0 \%$ & $15.2 \%$ \\
\hline & No data & 5 & 17 & $0.0 \%$ & $17.6 \%$ \\
\hline \multicolumn{2}{|c|}{ Total male } & 341 & 381 & $17.9 \%$ & $29.1 \%$ \\
\hline
\end{tabular}

*Total number of car/transit users surveyed to the corresponding gender and age.

Table 4 shows the degree of willingness to cycle and walk of those who stated to be willing to change to one of these modes.

TABLE 4 Degree of Willingness to Cycle and Walk

\begin{tabular}{|c|c|c|c|c|c|c|c|c|}
\hline \multirow[b]{3}{*}{ Age } & \multicolumn{4}{|c|}{ Degree of willingness to Cycle (\%) } & \multicolumn{4}{|c|}{ Degree of willingness to Walk (\%) } \\
\hline & \multicolumn{2}{|c|}{ Car users } & \multicolumn{2}{|c|}{ Transit users } & \multicolumn{2}{|c|}{ Car users } & \multicolumn{2}{|c|}{ Transit users } \\
\hline & Weak & Strong & Weak & Strong & Weak & Strong & Weak & Strong \\
\hline $18-30$ & $45.6 \%$ & $54.4 \%$ & $52.0 \%$ & $48.0 \%$ & $65.0 \%$ & $35.0 \%$ & $78.2 \%$ & $21.8 \%$ \\
\hline $31-50$ & $30.8 \%$ & $69.2 \%$ & $35.4 \%$ & $64.6 \%$ & $22.8 \%$ & $77.2 \%$ & $54.0 \%$ & $46.0 \%$ \\
\hline $51-65$ & $41.2 \%$ & $58.8 \%$ & $36.0 \%$ & $64.0 \%$ & $20.0 \%$ & $80.0 \%$ & $30.0 \%$ & $70.0 \%$ \\
\hline$>65$ & $33.3 \%$ & $66.7 \%$ & $16.7 \%$ & $83.3 \%$ & $0.0 \%$ & $100.0 \%$ & $18.8 \%$ & $81.2 \%$ \\
\hline No data & $0.0 \%$ & $0.0 \%$ & $0.0 \%$ & $0.0 \%$ & $0.0 \%$ & $0.0 \%$ & $100.0 \%$ & $0.0 \%$ \\
\hline Total & $37.5 \%$ & $62.5 \%$ & $44.0 \%$ & $56.0 \%$ & $36.8 \%$ & $63.2 \%$ & $55.1 \%$ & $44.9 \%$ \\
\hline
\end{tabular}

Respondents who stated in the last hypothetical scenario to keep on cycling whatever the travel costs savings, are estimated to have a strong willingness to change to cycling. 62.5 per cent of car users and 56 per cent of transit users stating to be willing to change would not be persuaded by high reductions in their travel costs to come back to their previous travel modes. There is some evidence that car users are less easily influenced compared to transit users by a decrease in their travel costs once they have decided to change to cycling. In addition, the older the user stating to be willing to cycle, the stronger willingness to change, especially if it refers to a usual transit user.

Similarly, respondents who stated in the last hypothetical scenario to keep on walking whatever the travel costs savings are estimated to have a strong willingness to change to 
walking. The results in table 4 suggest a positive correlation between those strongly willing to change to walking and their age, older people present lower percentages of weak willingness to change, while younger people (18-30 years old) are easily influenced by reductions in their travel costs to return to their motorized modes.

\section{MODEL ESTIMATION AND RESULTS}

The aim of this research is to test how strongly are respondents willing to change to nonmotorized modes, once they have stated to be willing to. To avoid the bias that would result from using a non-randomly selected sample that omit those respondents who state to be not willing to change to walking/cycling, a two stage estimator will be implemented. Thus, Heckman's two step model is used to this end.

\section{Model description}

Heckman's approach is based on a linear regression with a binary probit selection criterion model (12). In the first step a binary probit is calculated to model the initial stated willingness to change to cycling/walking. In the second step a linear regression is estimated for those stating to be willing to change, to test if they accept or not a reduction in their transportation costs to keep the decision to change.

\section{First step}

In order to determine the impact of different variables on the likelihood to cycle/walk, a probit model with two options is used: Yes, would change to cycling/walking, or No, would not change. The attributes determining choice are potentially all characteristics of the individual and trip, collected during the survey. The basic probit model formulation (13) is:

Prob $\left(\right.$ respondent $\mathrm{i}_{\mathrm{i}}$ states to be willing to cycle/walk $)=\operatorname{Pr}\left(\mathrm{z}_{\mathrm{i}}^{*}>0\right)=\operatorname{Pr}\left(\mathrm{Z}_{\mathrm{i}}=1\right)$

$$
\begin{array}{ll}
\mathrm{Z}_{\mathrm{i}}^{*}=\alpha^{\prime} \mathrm{w}_{\mathrm{i}}+u_{\mathrm{i}} & \\
\mathrm{Z}_{\mathrm{i}}=1 & \text { if } \mathrm{Z}_{\mathrm{i}}^{*}>0 \\
\mathrm{Z}_{\mathrm{i}}=0 & \text { if } \mathrm{z}_{\mathrm{i}}^{*} \leq 0
\end{array}
$$

where $\operatorname{Pr}$ is the normal distribution function, $\mathrm{z}_{\mathrm{i}}^{*}$ is the latent stated willingness to cycle/walk, $\mathrm{Z}_{\mathrm{i}}$ is $\mathrm{Z}_{\mathrm{i}}^{*}$ observed counterpart, $\alpha$ are a set of parameters to be estimated, $w$ are explanatory variables and $u$ is the error term which has a normal distribution $\mathrm{N}\left(0, \sigma_{u}{ }^{2}\right)$.

Thus, when $\mathrm{Z}_{\mathrm{i}}=1$ means respondent $\mathrm{i}$ states to be willing to change to cycling or walking and $\mathrm{z}_{\mathrm{i}}=0$ means respondent $\mathrm{i}$ states not to be willing to change.

To account for heterogeneity effects, we specify a random parameter model according to the following equation:

$$
\alpha_{\mathrm{i}}=\alpha+\Gamma \mathrm{vi}_{\mathrm{i}}
$$

The equation (1) decomposes each parameter into two parts: one is the average, which is fixed and common to all respondents, while the other is a matrix of standard deviations multiplied by an unobservable random term, $v_{i}$, which is independently normally distributed. 
We accommodate nonrandom parameters just by placing rows of zeros in the appropriate places in $\Gamma$.

\section{Second step}

Whether or not the respondent returns to car/transit under a reduction in monthly travel costs is only observed when $\mathrm{z}$ equals 1 . It has been assumed that those who accept a reduction in their travel costs and return to their motorized travel mode show a weak willingness to change compared with those related to a strong willingness to change that keep walking/cycling for the current journey even when faced with a decrease of travel costs of 90 per cent. A least squares regression is calculated:

Prob (respondent $\mathrm{i}_{\mathrm{i}}$ returns to car/transit under a reduction in travel costs) $=\operatorname{Pr}\left(\mathrm{y}_{\mathrm{i}}=1\right)$

$$
\mathrm{y}_{\mathrm{i}}=\beta^{\prime} \mathrm{x}_{\mathrm{i}}+\varepsilon_{\mathrm{i}}
$$

where $\beta$ are a set of parameters to be estimated, $x$ are explanatory variables and $\varepsilon$ is the error term which has a normal distribution $\mathrm{N}\left(0, \sigma_{\varepsilon}^{2}\right)$. Both error terms $\varepsilon_{\mathrm{i}}$ and $u_{\mathrm{i}}$ are correlated, $\rho_{\varepsilon u}$ is the correlation coefficient.

Thus, $y_{i}=1$ means respondent $\mathrm{i}$ returns to car/transit under a reduction in their travel costs, $\mathrm{y}_{\mathrm{i}}=0$ otherwise.

Maximum likelihood method is used to estimate model parameters.

To summarize, the dependent variables involved in the model are two, one for each step of the Heckman's approach. For the first step of the model, the dependent variable is respondent's stated willingness to change to cycling or walking that takes a value of 1 if respondent states to be willing to change and 0 otherwise; for the second step of the model, the dependent variable is the degree of willingness to change, 1 if respondent presents a weak degree of willingness to change to cycling/walking (respondent returns to car/transit under a reduction in the travel costs) and 0 otherwise, meaning respondent presents a strong degree of willingness to change to cycling/walking. A description of the explicative variables used in this modeling exercise is presented in Table 5.

\section{TABLE 5 Variable Definitions}

\begin{tabular}{ll}
\hline Variable & Definition \\
\hline Travel-related characteristics \\
\hline WORKSCHO & 1 if current journey purpose is work/school, 0 otherwise \\
SHOPPING & 1 if current journey purpose is shopping, 0 otherwise \\
\hline
\end{tabular}




\begin{tabular}{|c|c|}
\hline Variable & Definition \\
\hline NONSHOPP & Reference variable: current journey is different from work/shool and shopping \\
\hline MODEUSE & 1 if car is the usual travel mode for current journey, 0 if transit \\
\hline TIMEJOUR & Current journey time (minutes) \\
\hline COST & Monetary cost of current journey \\
\hline RESPOPAY & 1 if respondent pays the journey cost, 0 otherwise \\
\hline COSTKNOW & 1 if respondent knows about the cost of the current journey, 0 otherwise \\
\hline RENTKNOW & 1 if respondent knows about bike rental systems, 0 otherwise \\
\hline BIKEUSE & $\begin{array}{l}\text { Frequency of bicycle use: } 1 \text { (never), } 2 \text { (once a year), } 3 \text { (once a month), } 4 \text { (once a } \\
\text { week) }\end{array}$ \\
\hline \multicolumn{2}{|c|}{ Demographic characteristics } \\
\hline GENDER & 1 male, 0 female \\
\hline BIRTHYEA & Year of birth \\
\hline AGE & Age \\
\hline HOUSESIZ & Household size \\
\hline \multicolumn{2}{|c|}{ Socioeconomic characteristics } \\
\hline EMPLOYED & 1 if respondent is employed, 0 otherwise \\
\hline HOUSEWIF & 1 if respondent is housewife, 0 otherwise \\
\hline RETIRED & 1 if respondent is retired, 0 otherwise \\
\hline UNEMPLOY & reference category = unemployed \\
\hline STUDENT & 1 if respondent is student, 0 otherwise \\
\hline LEVELEDU & $\begin{array}{l}\text { Level of education: } 1 \text { (elementary), } 2 \text { (secondary), } 3 \text { (bachelor's degree), } 4 \\
\text { (master's degree) }\end{array}$ \\
\hline ELEMETAR & reference category =elementary studies \\
\hline SECDEGRE & 1 if respondent has a secondary degree, 0 otherwise \\
\hline BACDEGRE & 1 if respondent has a bachelor degree or higher, 0 otherwise \\
\hline INCOME & $\begin{array}{l}\text { Income level: } 1 \text { (less than } 15000 \text { euro per year), } 2 \text { ( } 15000-25000 \text { euro per year), } 3 \\
\text { (25000-35000 euro per year), } 5 \text { (more than } 35000 \text { euro per year) }\end{array}$ \\
\hline CARAVAIL & $\begin{array}{l}\text { Car availability: } 1 \text { (never), } 2 \text { ( } 2-3 \text { days per month), } 3 \text { (2-3 days per week), } 4 \\
\text { (always) }\end{array}$ \\
\hline BIKEAVAI & 1 if bicycle available, 0 otherwise \\
\hline \multicolumn{2}{|c|}{ Improvement measures selected } \\
\hline BIKE1 to BIKE7 & Cycling measures 1 to 7 as described in Table 1 . \\
\hline WALK1 to WAL & Walking measures 1 to 6 as described $\mathrm{i}$ \\
\hline
\end{tabular}

\section{Degree of willingness to change to cycling}

Results given by Heckman's two step model for the degree of willingness to change to cycling are summarized in the table below.

The highly significant value of lambda means the Heckman's model is appropriate to avoid a biased estimation of the degree of willingness to change to cycling by including data 
from those respondents who state to be not willing to change. Ignoring sample selection bias could have led to erroneous conclusions and poor policy implications because of the inconsistent estimates of the coefficients.

R-squared value for an OLS regression indicates how much of the variation in the dependent variable is explained by the variation in the set of independent variables. Low $\mathrm{R}$ squared's are common when studying individual travel behavior, and the value of R-squared in Table 6 is consistent with other results found in the literature. For example, Kitamura et al. (14), in a survey study that included travel diary data for households, found that regressions explaining the number of non-motorized trips undertaken by respondents had R-squared values ranging from 0.0256 to 0.0428. Similarly, Greenwald and Boarnet (15), in predicting individual non-work walking trips, found R-squared values ranging from 0.0509 to 0.0848 when using ordinary least squares.

As rho measures the correlation of disturbance in regression and selection criterion, the value of 0.5264 in Table 6 means a certain correlation exists between disturbances in the stated willingness to change to cycling and the degree of willingness to change to cycling.

\section{Second step: degree of willingness to change to cycling}

Next, results provided by the second step of Heckman's model are discussed. Positive signs of the explanatory variables are associated to a weak willingness to change to cycling, meaning respondents are easily persuaded by reductions in travel costs to give up cycling in the hypothetical scenario.

Whereas in the first step of the model car users are significantly less willing to change to cycling than transit users, the analysis of the results for the second step of the model shows that car users who have already changed to cycling present a stronger willingness to cycle compared to transit users. These results show that transit users are easily persuaded by reductions in travel costs to return to their transit mode while car users are less likely to be influenced by these reductions and keep on cycling once they have decided to change.

As expected, those who have higher monthly travel costs show a weaker degree of willingness to change, being easily influenced by decreases in their travel costs to give up cycling. Higher costs are related to longer distances traveled and therefore, more difficulties to switch to cycling.

Respondents stating to be willing to change to cycling under the implementation of cycling measure number 2 (cycle lanes clear of obstacles, motorized vehicles and pedestrians) present a weak willingness to change. This is the only improvement measure that significantly affects the degree of willingness to change to cycling, but its presence does not guarantee people to keep on cycling compared with monetary savings.

Retired respondents who have stated to be willing to cycle are less likely to return to their motorized mode under reductions in travel costs than students, probably because the older are more aware of the health benefits of being active and can spend more time traveling than students. Thus, in spite of the results provided by first step of the Heckman's model, students present a weak willingness to change to cycling because they tend to come back to their previous motorized mode under a scenario of decreasing travel costs. 
TABLE 6 Heckman's Two Step Model: Degree of Willingness to Change to Cycling

\begin{tabular}{|c|c|c|c|}
\hline Variable & Coefficient & b/St. Er. & $\mathbf{P}[|\mathbf{Z}|>\mathbf{z}] \mid$ \\
\hline \multicolumn{4}{|c|}{$\begin{array}{l}\text { RANDOM COEFFICIENTS PROBIT MODEL } \\
\text { Dep. variable: Stated willingness to change to cycling }\end{array}$} \\
\hline \multicolumn{4}{|c|}{ Nonrandom parameters } \\
\hline WORKSCHO & 0.2708 & 2.360 & 0.0183 \\
\hline MODEUSE & -0.7321 & -7.701 & 0.0000 \\
\hline RENTKNOW & 0.6139 & 6.466 & 0.0000 \\
\hline EMPLOYED & 0.5019 & 2.863 & 0.0042 \\
\hline HOUSEWIF & -1.3000 & -2.916 & 0.0036 \\
\hline \multicolumn{4}{|c|}{ Means for random parameters } \\
\hline Constant & -0.6955 & -3.124 & 0.0018 \\
\hline SHOPPING & -1.5437 & -5.768 & 0.0000 \\
\hline TIMEJOUR & -0.0544 & -8.305 & 0.0000 \\
\hline BIKEAVAI & 0.4949 & -5.286 & 0.0000 \\
\hline BACDEGRE & 0.2525 & 2.514 & 0.0119 \\
\hline RESPOPAY & 0.6539 & 5.108 & 0.0000 \\
\hline STUDENT & 1.4030 & 6.927 & 0.0000 \\
\hline \multicolumn{4}{|c|}{ Scale parameters for dists. of random parameters } \\
\hline Constant & 0.4604 & 9.752 & 0.0000 \\
\hline SHOPPING & 2.4689 & 7.654 & 0.0000 \\
\hline TIMEJOUR & 0.0196 & 8.045 & 0.0000 \\
\hline BIKEAVAI & 0.0255 & 0.395 & 0.0000 \\
\hline BACDEGRE & 0.2495 & 3.490 & 0.0005 \\
\hline RESPOPAY & 1.0258 & 16.186 & 0.0000 \\
\hline STUDENT & 0.6614 & 6.277 & 0.0000 \\
\hline Sample size & & 1388 & \\
\hline Restricted log likelihood & & -959.0371 & \\
\hline Log likelihood & & -850.3695 & \\
\hline \multicolumn{4}{|c|}{$\begin{array}{c}\text { LEAST SQUARES REGRESSION } \\
\text { Dep. variable: Degree of willingness to change to cycling }\end{array}$} \\
\hline Constant & 0.1401 & 2.124 & 0.0337 \\
\hline MODEUSE & -0.2078 & -3.674 & 0.0002 \\
\hline COST & 0.0018 & 3.112 & 0.0019 \\
\hline BIKE2 & 0.1336 & 2.291 & 0.0220 \\
\hline STUDENT & 0.1180 & 2.073 & 0.0382 \\
\hline RETIRED & -0.3383 & -2.338 & 0.0194 \\
\hline LAMBDA & 0.2743 & 3.544 & 0.0004 \\
\hline Sample size & & 648 & \\
\hline Restricted log likelihood & & -457.6789 & \\
\hline Log likelihood function & & -428.3808 & \\
\hline R-squared & & 0.0766 & \\
\hline
\end{tabular}




$\frac{0.5264}{\text { Rho }}$

Results given by Heckman's two step model for the degree of willingness to change to walking are summarized in the following table.

In this case, lambda is statistically non-significant, therefore no relevant selection bias would have arisen if these decisions were analyzed separately using a probit model. However, by including the results provided by Heckman's model, the comparison with the results from the degree of willingness to change to cycling results easier.

No correlation is found between disturbances in the stated willingness to change to walking and the degree of willingness to change to walking (rho $=-0.00748)$.

\section{First step: stated willingness to change to walking}

The analysis shows that young people are less likely to change to walking than old people. This is explained because older people are more aware of the health benefits of walking than younger people. Similarly, Curtis et al. (4) discovered that younger (20-24 years) are least likely to switch from car to other transportation mode. Recently, Bricka et al. (22) indicated that those aged between 36 and 65 years old were more likely to walk.

Those who know their transportation costs state to be less willing to walk. Usually, the higher the transportation costs, the more aware people are of them, and the more distance is traveled. So it is reasonable that the propensity to walk is lower.

Work/school related journeys state to be less associated to walk than non-commuting journeys, but they are more related to cycling. It is reasonable that work/school trips currently made by car or transit are more difficult to be transferred to walk because travel time is an issue. However, this type of journeys are more likely to be done by bicycle since cycling speed is higher than walking speed, reducing travel time to an admissible level.

There is a common influence on the propensity to walk and cycle. On one hand, those usually traveling by transit state to be more willing to both cycle and walk than those using car. The explanation could be that car users usually travel higher distances or they have time restrictions, which makes difficult to switch to non-motorized travel modes. On the other hand, the longer the journey in terms of time the less likely to change to non-motorized travel modes as can be easily understood.

\section{Second step: degree of willingness to change to walking}

Next, results provided by the second step of Heckman's selection model are discussed. Positive signs of the explanatory variables are associated to a weak willingness to change to walking.

Commuting journeys present a weaker degree of willingness to be changed to walking than non-commuting journeys, meaning that work/school related journeys are more susceptible to be influenced by decreased travel costs and are more likely to induce respondents to return to car/transit.

Car users who have already changed to walking present a stronger willingness to walk compared to transit users. Using a car is also related to a stronger willingness to cycle, as mentioned earlier. 
TABLE 7 Heckman's Two Step Model: Degree of Willingness to Change to Walking

\begin{tabular}{|c|c|c|c|}
\hline Variable & Coefficient & b/St. Er. & $\mathbf{P}[|\mathbf{Z}|>\mathbf{z}] \mid$ \\
\hline \multicolumn{4}{|c|}{$\begin{array}{c}\text { RANDOM COEFFICIENTS PROBIT MODEL } \\
\text { Dep. variable: Stated willingness to change to walking }\end{array}$} \\
\hline \multicolumn{4}{|l|}{ Nonrandom parameters } \\
\hline BIRTHYEA & -0.0170 & -3.767 & 0.0002 \\
\hline COSTKNOW & -0.3509 & -1.919 & 0.0550 \\
\hline \multicolumn{4}{|c|}{ Means for random parameters } \\
\hline Constant & 3.1401 & -8.304 & 0.0000 \\
\hline WORKSCHO & -0.4572 & -3.740 & 0.0002 \\
\hline MODEUSE & -0.9518 & -7.987 & 0.0000 \\
\hline TIMEJOUR & -0.0733 & -7.987 & 0.0000 \\
\hline \multicolumn{4}{|c|}{ Scale parameters for dists. of random parameters } \\
\hline Constant & 0.0919 & 1.650 & 0.0989 \\
\hline WORKSCHO & 0.2196 & 3.026 & 0.0025 \\
\hline MODEUSE & 0.2609 & 3.264 & 0.0011 \\
\hline TIMEJOUR & 0.3637 & 8.785 & 0.0000 \\
\hline Sample size & & 1412 & \\
\hline Log likelihood & & -391.5397 & \\
\hline \multicolumn{4}{|c|}{$\begin{array}{c}\text { LEAST SQUARES REGRESSION } \\
\text { Dep. variable: Degree of willingness to change to walking }\end{array}$} \\
\hline Constant & 0.9918 & 7.765 & 0.0000 \\
\hline WORKSCHO & 0.1568 & 2.508 & 0.0122 \\
\hline MODEUSE & -0.2271 & -3.523 & 0.0004 \\
\hline RESPOPAY & -0.1838 & -2.250 & 0.0244 \\
\hline COST & 0.0022 & 2.474 & 0.0134 \\
\hline BACDEGRE & -0.1384 & -2.537 & 0.0112 \\
\hline AGE & -0.0088 & -4.400 & 0.0000 \\
\hline LAMBDA & -0.0032 & -0.110 & 0.9128 \\
\hline Sample size & & 281 & \\
\hline Restricted log likelihood & & -203.5464 & \\
\hline Log likelihood function & & -157.1904 & \\
\hline R-squared & & 0.2599 & \\
\hline Rho & & -0.00748 & \\
\hline
\end{tabular}

Another expected result is that respondents paying for the costs of the current journey show a strong degree of willingness to change. Then, once they have decided to switch, respondents tend to keep on walking because they are aware of the benefits from using a noncost travel mode. 
Those who have higher monthly travel costs show a weaker degree of willingness to change to walking, being easily influenced by decreases in their travel costs to give up walking. The same result was found when studying the degree of willingness to change to cycling. Higher costs are related to longer distances traveled and therefore, more difficulties to switch to walking. Similarly, Da Penha Sanches et al. (23) found that for trips longer than 4 kilometers, the probability of walking is almost zero.

The education status and age also influences the degree of willingness to walk. Those who have a bachelor or higher degree are more associated with a strong willingness to change to walking than having an elementary degree. Possibly, more educated and older people are better informed of the benefits of walking and are less likely to be persuaded by reductions in travel costs to give up walking. Kemperman et al. (24) studied the influences of the built environment on walking and cycling in aging people and suggested that medium and highly educated respondents are also more often bike riders and walkers than less-educated respondents.

\section{CONCLUSIONS}

This paper presents the results of an analysis of the degree of willingness to change to walking or cycling for certain trips currently undertaken by car or transit, aimed to reduce the uncertainty between the readiness to change stated in travel surveys and the real potential to shift trips to walking or cycling. The survey data was collected to a sample of car and transit users in the city of Valencia. In this novel approach, respondents who state to be willing to change were presented a hypothetical scenario where they have already changed to the nonmotorized mode selected and where reductions in their travel costs can persuade participants to come back to their motorized modes; the willingness to change of those giving up walking/cycling is assessed as weak compared to those strongly willing to change that don't reverse their decision.

A Heckman's two step model is estimated. The results indicate that car users present a stronger willingness to change to walking and cycling compared to transit users, in spite of prior results addressing transit users to be more willing to change. Thus, car users decided to walk or cycle for the current journey are less susceptible to be influenced by reductions in their travel costs than transit users. This phenomenon could be related to the existence of a group of car drivers looking forward to give up driving and willing to move out of their cars, concerned about environmental problems or facing economic difficulties. The fact that transit users present a weaker degree of willingness to change to walking or cycling, could be explained because they usually travel longer distances or they may consider that the environmental impacts caused by transit are not significant.

As expected, commuting journeys are less likely to be changed to walking than to cycling. In addition, results provided in first step of Heckman's model proved that employed respondents are more likely to change to cycling than those unemployed-result that supports the previous finding. However, work and school related journeys were not found to be significant at the analysis of the degree of willingness to change to cycling. In the case of walking, results have shown that those respondents who decide to switch to walking are easily persuaded by reductions in their travel costs to give up walking, resulting in a weak willingness to change. 
Other results are related to socio-demographic characteristics. In both cycling and walking, old respondents show a stronger willingness to change than young respondents, revealing this group of people is highly likely to change under the implementation of improvement measures. Additionally, those having a bachelor's degree or a higher degree that state to be willing to change to walking tend to reaffirm their decision, showing a strong willingness to switch.

Findings provided by the present study can also be used to design policies and actions to encourage drivers to reduce their car use for short trips more efficiently. For example, as none of the walking or cycling improvement measures is found directly related to a strong willingness to change to walking or cycling in the city of Valencia, policy makers should focus on the application of car use restriction strategies to lead to effective modal change. Moreover, as car users present a strong willingness to change to walking and cycling compared to transit users, pedestrianizing certain areas of the city could increase both travel modes.

One of the findings of our research is that older people have a strong readiness to change to walking and cycling. Then, transportation planners in the city of Valencia could consider offering a lower price to older people purchasing an annual subscription to the public bicycle rental system in the city to encourage the modal shift.

As those having a bachelor's degree or a higher degree that state to be willing to change to walking tend to have a strong willingness to switch, travel awareness campaigns to encourage walking for short trips should be implemented at the university, before these students become graduates. In addition, as mentioned before, work/school related journeys have a great potential to be transferred to cycling, therefore, travel awareness campaigns should be extended to cycling, considering there is a significant amount of students who may be considering change.

Finally, the methodology of the survey presented would also enable policy makers to approximate to the real impact of the implementation of a particular improvement measure aimed at reducing car and transit use by encouraging walking and cycling in a city, helping practitioners as a decision-making tool.

\section{REFERENCES}

1. Pucher, J., J. Dill and S. Handy (2010) Infraestructure, programs, and policies to increase bicycling: An international review. Preventive Medicine 50, pp. 106-125.

2. Handy, S., Weston, L. and Mokhtarian, P. L. (2005) Driving by choice or necessity? Transportation Research Part A, 39, pp. 183-203.

3. Litman, T.A. (2008) Valuing service quality improvements in transportation planning, Transportation Research Board 87th Annual Meeting Compedium of Papers.

4. Curtis, C. \& Headicar, P. (1997) Targeting Travel Awareness Campaigns, Transport Policy, 4, pp.-57-65.

5. Kingham, S., Dickinson, J. \& Copsey, S. (2001) Travelling to Work: Will People move Out of their Car, Transport Policy, 8, pp.-151-160.

6. Wardman, M., Tight, M. and Page, M. (2007) Factors Influencing the Propensity to Cycle to Work. Transportation Research A, 41, pp.339-350. 
7. Shannon, T., Giles-Corti, B., Pikora, T., Bulsara, M., Shilton, T. \& Bull, F. (2006) Active Commuting in a University Setting: Assessing Commuting Habits and Potential for Modal Change, Transport Policy, 13, pp.-240-253.

8. Department for Transport, (2012) British Social Attitudes Survey 2011: public attitudes towards transport.

9. Generalitat Valenciana (2009). Encuesta de Movilidad de Personas en el Área de Valencia. Unpublished Report.

10. WALCYNG (1997) How to Enhance Walking and Cycling Instead of Shorter Car Trips and to Make these Modes Safer, http://cordis.europa.eu/transport/src/walcyngrep.htm, accessed 26/07/2012.

11. Guria, J., Leung, J., Jones-Lee, M. and Loomes, G. (2005) The willingness to accept value of statistical life relative to the willingness to pay value: evidence and policy implications, Environmental and Resource Economics, 32, pp. 113-127.

12. Heckman, James J. (1979) Sample Selection Bias as a Specification Error, Econometrics, 47 (1), pp.-153-161.

13. Bliss, C. (1934) The Method of Probits, Science, 79 (2037), pp.38-39.

14. Kitamura, Ryuichi, Patricia Mokhtarian, and Laura Laidet. (1997) A Micro-Analysis of Land Use and Travel in Five Neighborhoods in the San Francisco Bay Area. Transportation 23, pp. 125-158.

15. Greenwald and Boarnet. (2002) Built Environment as Determinant of Walking Behavior: Analyzing Nonwork Pedestrian Travel in Portland, Oregon. Transportation Research Record 1780, pp. 33-42.

16. Ortúzar, J.de D., Iacobelli, A. and Valeze, C. (2000) Estimating the demand for a cycleway network, Transportation Research Part A 34, pp. 353-373.

17. Kim, S. and G. F. Ulfarsson (2008). Curbing automobile use for sustainable transportation: analysis of mode choice on short home-based trips. Transportation 35(6), pp. 723-737.

18. Ferdous, N., Pendyala, R., Bhat, C. and Konduri, K. (2011) Modeling the Influence of Family, Social Context, and Spatial Proximity on Use of Nonmotorized Transport Mode, Transportation Research Record 2230, pp. 111-120.

19. Bovy, P.H.L. and Bradley, M.A. (1985) Route choice analyzed with stated preference approaches. Transportation Research Record 1037, pp. 11-20.

20. Ryley, T. J. (2006) Estimating cycling demand for the journey to work or study in West Edinburgh, Scotland. Transportation Research Record 1982, pp 187-193.

21. Hunt, J. D. and Abraham, J. E. (2007) Influences on bicycle use. Transportation, 34, pp. 453-470.

22. Bricka, S., Sener, I.N., Dusza, C. and Hudson, J.G. (2011) Factors Influencing Walking in a Small Urban Region. Transportation Research Board 91 st Annual Meeting.

23. Da Penha Sanches, S. and Serra de Arruda, F. (2002) Incorporating Nonmotorized Modes in a Mode Choice Model, Transportation Research Record 1818, pp.89-93.

24. Kemperman, A. and Timmermans, H. (2009) Influences of Built Environment on Walking and Cycling by Latent Segments of Aging Population, Transportation Research Record 2134, pp.1-9. 